\title{
Dural arteriovenous fistula, a rare cause of rapidly progressive dementia in a patient with bilateral thalamic lesions: a case report
}

\author{
Jing Zhang ${ }^{1 \#}$, Hongzhou Duan ${ }^{2 \#}$, Haiqiang Jin ${ }^{1}$, Yinglin Leng ${ }^{1}$, Jing Chen ${ }^{1}$, Wei Zhang ${ }^{1}$, Yining Huang ${ }^{1}$ \\ ${ }^{1}$ Department of Neurology, Peking University First Hospital, Beijing, China; ${ }^{2}$ Department of Neurosurgery, Peking University First Hospital, \\ Beijing, China \\ \#These authors contributed equally to this work. \\ Correspondence to: Wei Zhang. Department of Neurology, Peking University First Hospital, Beijing, China. Email: neurozw@163.com.
}

\begin{abstract}
There are many causes of bilateral thalamic lesions, but few cases of dural arteriovenous fistula (DAVF) associated with such lesions have been reported previously. Here, we describe an adult man with reversible rapid progressive dementia (RPD) in whom bilateral thalamic lesions were caused by a DAVF that had six supply arteries and drained into both the venous sinus and cortical veins. A 53-year-old man presented with memory decline and abnormal behavior. Head computed tomography (CT) revealed insignificant low density in the bilateral thalami and high density in the right occipital lobe. Brain magnetic resonance imaging showed hyperintensities in the thalami on T2-weighted images. Magnetic resonance venogram revealed no sign of the straight sinus, but multiple tortuous vessels in the cistern of the vein of Galen. Digital subtraction angiography revealed DAVFs near the tentorium cerebelli draining into the vein of Galen, which caused the vasogenic oedema of the thalami. The patient was then treated by transarterial embolization of the feeders. He gradually recovered after the surgery. RPD with bithalamic lesions caused by DAVF is rare but reversible. Therefore, the early recognition and intervention of DAVFs is crucial for the good prognosis of patients so that fistulas can be embolized in time.
\end{abstract}

Keywords: Bithalamic lesions; dural arteriovenous fistula (DAVF); rapid progressive dementia (RPD); case report

Submitted Jul 25, 2020. Accepted for publication Feb 02, 2021.

doi: 10.21037/apm-20-1481

View this article at: http://dx.doi.org/10.21037/apm-20-1481

\section{Introduction}

Rapid progressive dementia (RPD) has many causes, among which bithalamic lesions are rarely reported. The thalamus is a deep gray matter structure located on either side of the third ventricle. It has multiple nuclei with different functions, which mainly regulate consciousness, sleep, and alertness. Metabolic or toxic disorders, such as demyelination, infection, neoplasm, and vascular occlusion, may manifest as bilateral thalamic lesions (1). Of these, dural arteriovenous fistulas (DAVFs) are a rarely reported cause. DAVFs are vascular malformations in which meningeal arteries drain directly into dural venous sinuses, meningeal veins, or subarachnoid veins. DAVFs present mostly in adulthood and are located in the transverse, sigmoid, and cavernous sinuses (2). DAVFs in the vein of Galen are relatively uncommon and have only been described in a few cases. Here, we describe an adult man with reversible RPD in whom bilateral thalamic lesions were caused by a DAVF that had six supply arteries, and drained into both the venous sinus and cortical veins. We present this case in accordance with the CARE reporting checklist (available at http://dx.doi.org/10.21037/apm-20-1481).

\section{Case presentation}

A 53-year-old man was referred to our center because of abnormal behavior. Two weeks previously, he had started to present with memory decline and abnormal behavior. For example, he asked his wife to charge his shoes and paint his white shoes black. He forgot his bank card passwords. Moreover, he was a driver but he was unable to park the car 
correctly and often sat in silence while working. Meanwhile, his personality changed. He stopped losing his temper and began to giggle for no reason. He had no fever, headache, vomiting, seizure, or hallucination. In addition, no vaccination or drug abuse was revealed. He was diagnosed with glaucoma 1 year previously and had hypertension for 10 years. Heavy smoking and drinking were noted.

Physical examinations showed memory decline (both short and long term) and poor calculation skills. The patient's Mini-Mental State Examination (MMSE) score was 20 (he lost points on time orientation, calculation, and short-term memory) and his Montreal Cognitive Assessment (MoCA) score was 12 (he lost points on executive function, naming, memory, attention, calculation, verbal fluency, abstract, and orientation) with a middleschool education (Table 1). There was no other focal deficit

Table 1 MMSE and MoCA scores before and after the surgery

\begin{tabular}{lcc}
\hline & Before surgery & After surgery \\
\hline MMSE & 20 & 25 \\
MoCA & 13 & 22 \\
Visuospatial/executive & 2 & 3 \\
Naming & 2 & 3 \\
Attention & 3 & 6 \\
Language & 1 & 2 \\
Abstraction & 1 & 1 \\
Delayed recall & 0 & 2 \\
Orientation & 4 & 5 \\
\hline
\end{tabular}

MMSE, mini-mental state examination; MoCA, Montreal Cognitive Assessment. present in nervous system examinations.

Head computed tomography (CT) revealed insignificant low density in the bilateral thalami and high density in the right occipital lobe (Figure 1). Brain magnetic resonance imaging (MRI) demonstrated iso-hypointensities in the bilateral thalami on T1-weighted imaging, diffuse and symmetric hyperintensities with no prominent spaceoccupied effect on T2 fluid-attenuated inversion recovery imaging, isointensities on diffusion-weighted imaging (DWI), hyperintensities on apparent diffusion coefficient (ADC), and mixed signals on $\mathrm{T} 2{ }^{*}$-weighted imaging. Tortuous vessels were also noted in the sagittal view on T2*-weighted imaging (Figure 2).

Occlusion of the artery of Percheron was excluded because there were no hyperintensities on DWI. Wernicke encephalopathy was first considered on account of the patient's heavy drinking. However, his symptoms were not improved after vitamin B1 injection; thus, other causes needed to be considered.

The mixed signals on $\mathrm{T} 2{ }^{*}$-weighted imaging were noted. Furthermore, magnetic resonance venogram (MRV) revealed no sign of the straight sinus, but multiple tortuous vessels in the cistern of the vein of Galen (Figure 3), which indicated that the bithalamic lesions were caused by the blockage of venous return. Digital subtraction angiography (DSA) revealed a DAVF (Cognard type IIa + b) near the tentorium cerebelli, draining into the vein of Galen and cortical veins, which caused the vasogenic oedema of the thalami. The fistula had feeders from the bilateral middle meningeal arteries, bilateral meningohypophyseal trunks, right posterior meningeal artery, and right posterior cerebral artery (Figure 4).

The patient was treated by transarterial embolization
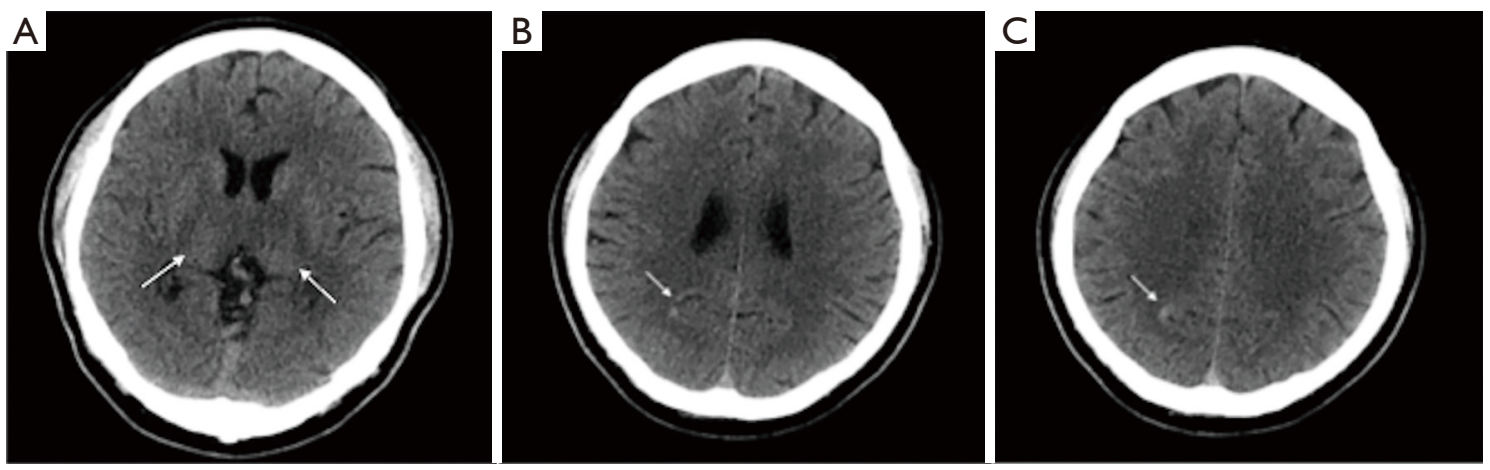

Figure 1 Head CT. (A) Insignificant low density (arrow) in the bilateral thalami. (B,C) Stripe-like high density (arrow) in the right occipital lobe. CT, computed tomography. 

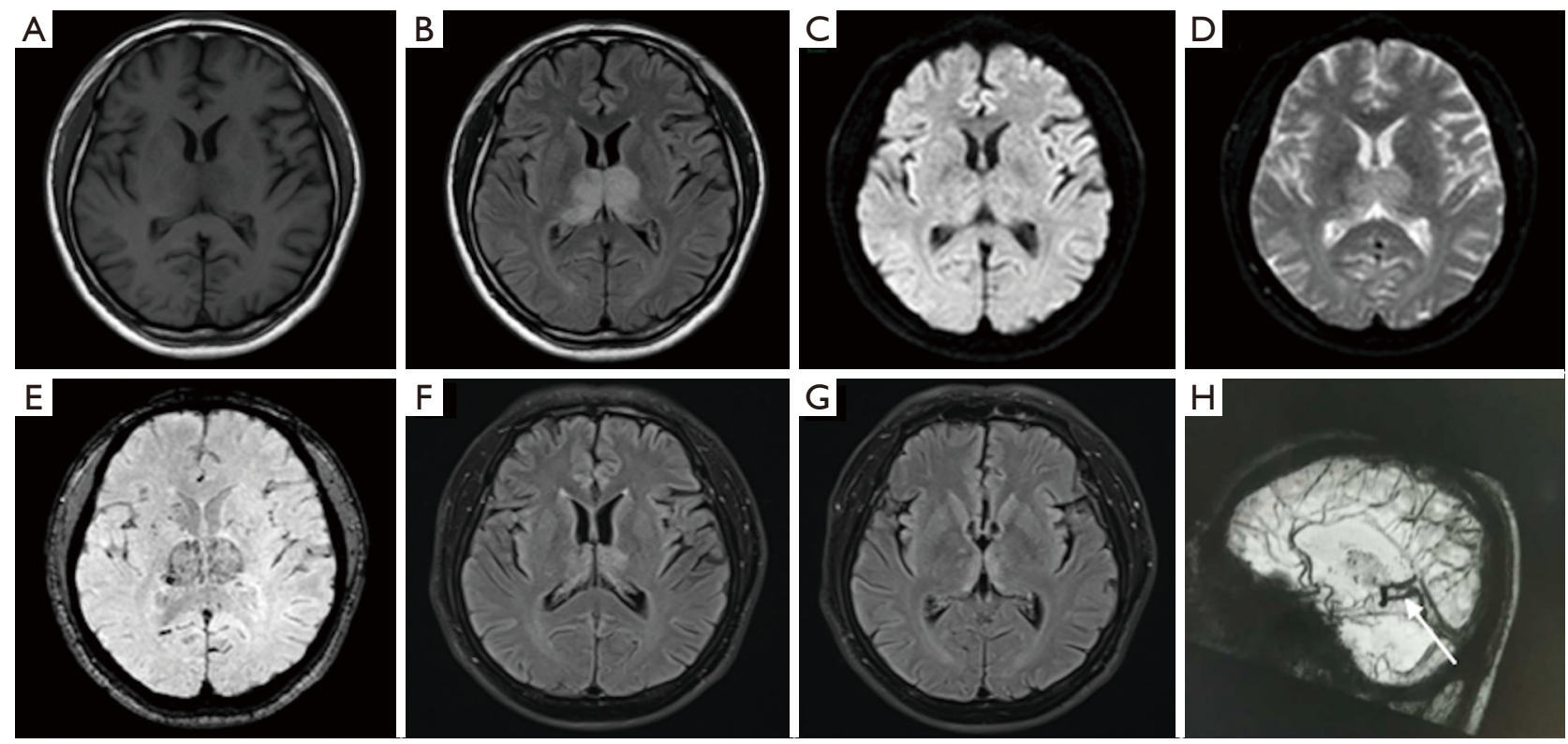

Figure 2 Brain MRI. (A) Iso-hypointensities in the bilateral thalami on T1-weighted images. (B) Hyperintensities on T2 FLAIR images. (C) Isointensities on DWI. (D) Hyperintensities on ADC. (E) Mixed signals on T2*-weighted imaging. (F,G) After embolization, the hyperintensities in the bilateral thalami disappeared. (H) Tortuous vessels (arrowhead) in the sagittal view on T2*-weighted imaging. ADC, apparent diffusion coefficient; DWI, diffusion-weighted imaging; FLAIR, fluid-attenuated inversion recovery; MRI, magnetic resonance imaging.
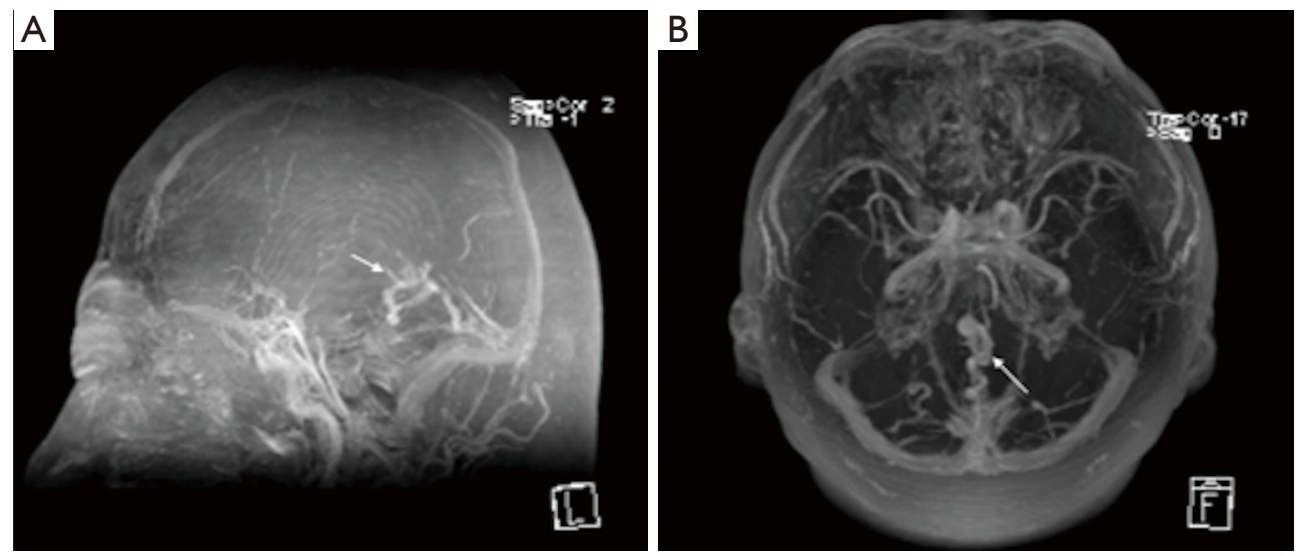

Figure 3 Contrast-enhanced MRV. There were no signs of the straight sinus or multiple tortuous vessels in the cistern of the vein of Galen (arrowhead) in either the lateral (A) or inferior (B) position. MRV, magnetic resonance venogram.

of the feeders. After surgery, the vein disappeared from the arterial phase. MRI conducted 6 days after surgery revealed prominent improvements (Figure 2), and the patient's cognitive function gradually recovered. His MMSE score after surgery was 25 , and his MoCA score was 22 (Table 1). The patient thanked his doctors for their efforts toward his recovery. All procedures performed in the studies involving human participants were in accordance with the ethical standards of the institutional and national research committees and with the Helsinki Declaration (as revised in 2013). Written informed consent was obtained from the patient. This research was approved by the Ethics Committee of Peking University (PU IRB; No. IRB00001052-17018). 

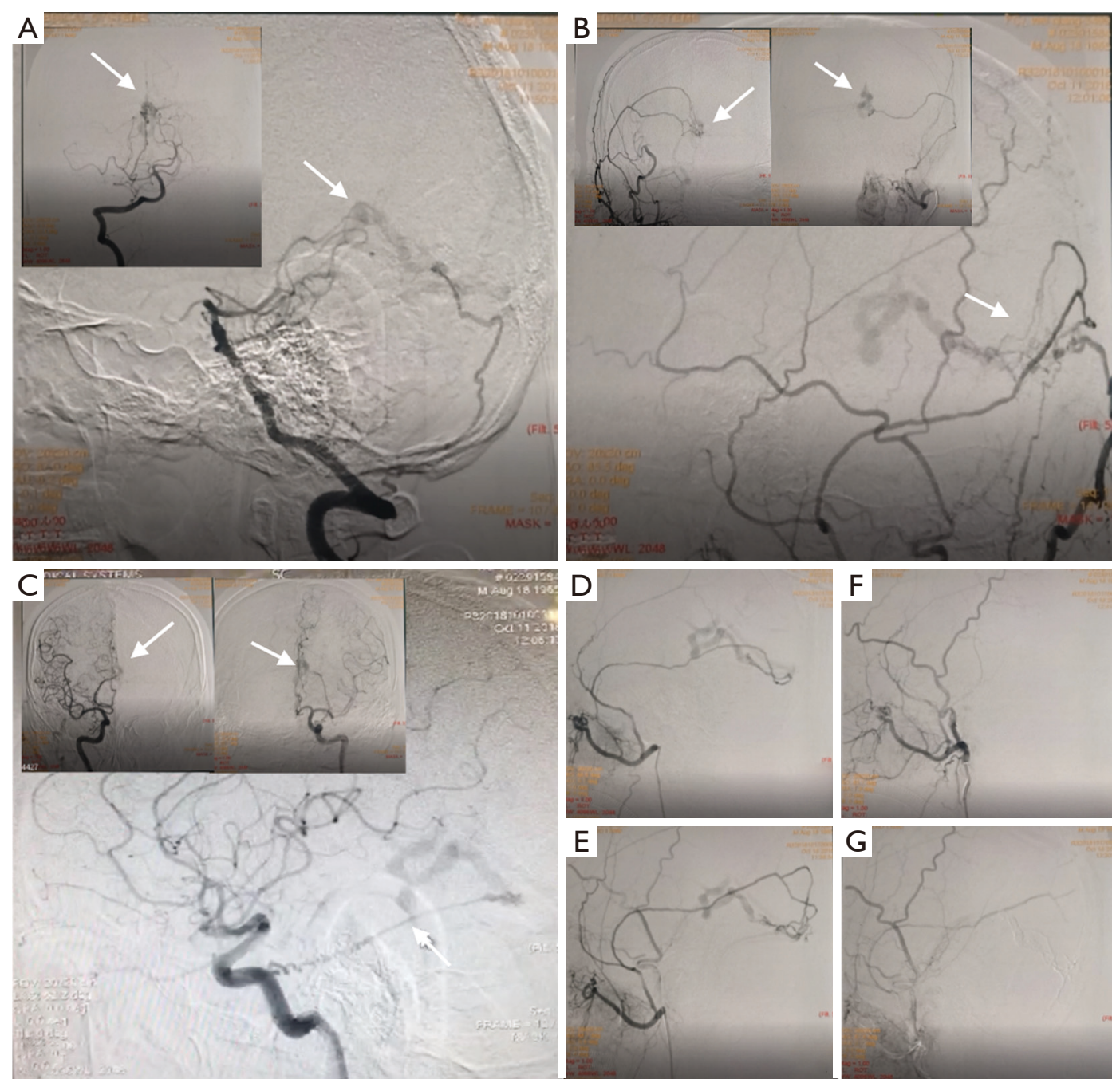

Figure 4 DSA of the DAVF. DSA revealed a DAVF near the tentorium cerebelli, draining into the vein of Galen. There were feeders from: the right posterior cerebral artery (A, arrowhead); the bilateral middle meningeal arteries (B, arrowhead); and the bilateral meningohypophyseal trunks (C, arrowhead). (D,E) Before the embolization. (F,G) After the embolization. DSA, digital subtraction angiography; DAVF, dural arteriovenous fistula.

\section{Discussion}

A wide spectrum of disorders can cause RPD. The most common differential diagnoses include Creutzfeldt-Jakob disease, rapidly progressive Alzheimer's disease, dementia with Lewy bodies, and other neurodegenerative diseases, cerebrovascular dementia, or inflammatory diseases (3). However, RPD caused by bilateral thalamic lesions with DAVF has rarely been reported. The prominent cognitive impairment of our patient was severe memory loss and personality change (apathy), as well as language, visuospatial/ executive, attention, and orientation impairments; these findings are in line with thalamic disease. It is worth noting that the RPD in our patient was reversed after surgery. Therefore, in patients who present with RPD accompanied by thalamic lesions, the possibility of vessel diseases, and especially DAVFs, should be considered.

In the present case, RPD was the only symptom, and no other positive clinical manifestations or signs were noted. Patients with DAVFs may also present pulsatile tinnitus, intracranial hemorrhage, and non-hemorrhagic neurological deficits such as seizures, parkinsonism, cerebellar symptoms, apathy, failure to thrive, and cranial nerve abnormalities. Symptoms are related to lesion location and the pattern 
Table 2 Patients with bilateral thalamic lesions caused by DAVFs in the literature

\begin{tabular}{|c|c|c|c|c|c|c|c|}
\hline $\begin{array}{l}\text { Case } \\
\text { No. }\end{array}$ & $\begin{array}{l}\text { Age (years), } \\
\text { sex }\end{array}$ & $\begin{array}{l}\text { Time of } \\
\text { diagnosis }\end{array}$ & Clinical presentation & $\begin{array}{l}\text { MRI features (on } \\
\text { T2 Flair-weighted) }\end{array}$ & $\begin{array}{l}\text { Supply arteries and } \\
\text { drainage veins of } \\
\text { fistula }\end{array}$ & $\begin{array}{l}\text { dAVF } \\
\text { classification }\end{array}$ & $\begin{array}{l}\text { Outcome after } \\
\text { surgery (endovascular } \\
\text { embolization) }\end{array}$ \\
\hline 3 & $50, M$ & $\begin{array}{l}\text { Many } \\
\text { years }\end{array}$ & Abnormal behavior & $\begin{array}{l}\text { Patchy } \\
\text { hyperintensities }\end{array}$ & $\begin{array}{l}\text { RMTA, RMMA, ROA } \\
\text { to the vein of Galen, } \\
\text { the Rosenthal veins } \\
\text { and BICV }\end{array}$ & UK & $\begin{array}{l}\text { Clinical and imaging } \\
\text { Improvement (6) }\end{array}$ \\
\hline 4 & $53, \mathrm{M}$ & $\begin{array}{l}\text { Ten } \\
\text { days }\end{array}$ & $\begin{array}{l}\text { Confusion and } \\
\text { memory problems }\end{array}$ & $\begin{array}{l}\text { Diffused and } \\
\text { symmetrical } \\
\text { hyperintensities }\end{array}$ & $\begin{array}{l}\text { MMA and } \\
\text { inferolateral trunks } \\
\text { of ICA to straight } \\
\text { sinus and the vein of } \\
\text { Galen }\end{array}$ & Zipfel 2S & $\begin{array}{l}\text { Clinical and imaging } \\
\text { Improvement ( } 7)\end{array}$ \\
\hline 5 & $59, \mathrm{M}$ & $\begin{array}{l}\text { Five } \\
\text { days }\end{array}$ & $\begin{array}{l}\text { Memory deficits, } \\
\text { aphasia and } \\
\text { confabulation }\end{array}$ & $\begin{array}{l}\text { Asymmetrical } \\
\text { hyperintensities }\end{array}$ & $\begin{array}{l}\text { LOA and BPMA to } \\
\text { the vein of Galen } \\
\text { and BICV }\end{array}$ & Zipfel 3S & $\begin{array}{l}\text { Clinical and imaging } \\
\text { Improvement ( } 7)\end{array}$ \\
\hline 6 & $60, M$ & $\begin{array}{l}\text { Four } \\
\text { days }\end{array}$ & $\begin{array}{l}\text { Confusion and } \\
\text { memory deficits }\end{array}$ & $\begin{array}{l}\text { Asymmetrical } \\
\text { hyperintensities }\end{array}$ & $\begin{array}{l}\text { ROA to the vein of } \\
\text { Galen and ICV }\end{array}$ & Zipfel $3 S$ & $\begin{array}{l}\text { Clinical and imaging } \\
\text { Cured (7) }\end{array}$ \\
\hline 7 & Middle-aged & UK & $\begin{array}{l}\text { Shuffling gait, } \\
\text { somnolence and } \\
\text { diplopia }\end{array}$ & $\begin{array}{l}\text { Diffused and } \\
\text { symmetrical } \\
\text { hyperintensities }\end{array}$ & UK & Cognard IV & $\begin{array}{l}\text { Died of basal } \\
\text { ganglia hemorrhage } \\
\text { secondary to DAVF (8) }\end{array}$ \\
\hline
\end{tabular}

$\mathrm{BICV}$, bilateral internal cerebral veins; BMHT, bilateral meningohypophyseal trunks; BMMA, bilateral middle meningeal arteries; BOA, bilateral occipital arteries; BPMA, bilateral posterior meningeal arteries; DAVF, dural arteriovenous fistula; ICA, internal carotid arteries; ICV, internal cerebral veins; LMMA, left middle meningeal artery; LOA, left occipital artery; LPMA, left posterior meningeal artery; MMA, middle meningeal arteries; RMMA, right middle meningeal artery; RMTA, right medial tentorial artery; ROA, right occipital artery; RPCA, right posterior cerebral artery; RPMA, right posterior meningeal artery; UK, unknown.

of venous drainage (2). Bilateral thalamic lesions are uncommon, and those caused by DAVFs are even rarer. We reviewed the cases reported in PubMed (summarized in Table 2). DAVF-induced bithalamic lesions were almost exclusively observed in men, and were most common in the fifth to seventh decades of life (range, 51-71 years). Most of the courses of the disease were acute or subacute. The time to diagnosis from initial symptoms were a few days, except in two cases that were confirmed after 6 months and many years. Nearly all patients presented with progressive cognitive dysfunction, especially memory impairments. Three of nine patients had additional neurological deficits, including hemiparesis, aphasia, confabulation, shuffling gait, diplopia, and slurred speech.

Bithalamic lesions on MRI can be symmetrical or asymmetrical, and diffused or patchy. Most supply arteries of fistulas are middle meningeal arteries, occipital arteries, or posterior meningeal arteries. The drainage veins can be 
the vein of Galen, basal veins of Rosenthal, internal cerebral veins, or straight sinus. In our case, the fistula had six supply arteries: the bilateral middle meningeal arteries, bilateral meningohypophyseal trunks of the internal carotid arteries, right posterior meningeal artery, and right posterior cerebral artery. In addition, the fistula drained into not only the venous sinus, but also the cortical veins, which caused the tortuous vein and restricted venous return. The bithalamic lesion was caused by vasogenic oedema, which was confirmed by MRI features and was consistent with the region of venous drainage. Most previous cases have had a good prognosis, except one patient who died of a basal ganglia hemorrhage secondary to DAVF. Furthermore, clinical and imaging changes are generally reversible after surgery.

In the present case, head CT and brain MRI provided early clues to the diagnosis of DAVF. The high density in the right occipital lobe on $\mathrm{CT}$, hyperintensities on $\mathrm{ADC}$, and tortuous vessels on $\mathrm{T}^{*}$ may indicate abnormal flow in the straight sinus; this was later confirmed by MRV and DSA. Thus, CT is necessary and valuable for the early recognition of DAVFs.

In conclusion, RPD with bithalamic lesions caused by DAVF is rare but reversible. Head CT and brain MRI can provide early clues for its diagnosis. The early recognition and intervention of DAVFs is crucial for good prognosis, so that fistulas can be embolized in time.

\section{Acknowledgments}

We thank Bronwen Gardner, PhD, from Liwen Bianji, Edanz Editing China (www.liwenbianji.cn/ac), for editing the English text of a draft of this manuscript.

Funding: This work was supported by the ULM-PUHSC Joint Institute for Translational and Clinical Research (Grant No. PKU2017ZC001-5) and Natural Science Foundation of Tibet Autonomous Region (Grant No. XZ2017ZR-ZY020).

\section{Footnote}

Reporting Checklist: The authors have completed the CARE reporting checklist. Available at http://dx.doi.org/10.21037/ apm-20-1481

Conflicts of Interest: All authors have completed the ICMJE uniform disclosure form (available at http://dx.doi. org/10.21037/apm-20-1481). The authors have no conflicts of interest to declare.
Ethics Statement: The authors are accountable for all aspects of the work in ensuring that questions related to the accuracy or integrity of any part of the work are appropriately investigated and resolved. All procedures performed in the studies involving human participants were in accordance with the ethical standards of the institutional and national research committees and with the Helsinki Declaration (as revised in 2013). Written informed consent was obtained from the patient. This research was approved by the Ethics Committee of Peking University (PU IRB; No. IRB00001052-17018).

Open Access Statement: This is an Open Access article distributed in accordance with the Creative Commons Attribution-NonCommercial-NoDerivs 4.0 International License (CC BY-NC-ND 4.0), which permits the noncommercial replication and distribution of the article with the strict proviso that no changes or edits are made and the original work is properly cited (including links to both the formal publication through the relevant DOI and the license). See: https://creativecommons.org/licenses/by-nc-nd/4.0/.

\section{References}

1. Özgür A, Esen K, Kaleağası H, et al. Bilateral thalamic lesions: A pictorial review. J Med Imaging Radiat Oncol 2017;61:353-60.

2. Gandhi D, Chen J, Pearl M, et al. Intracranial dural arteriovenous fistulas: classification, imaging findings, and treatment. AJNR Am J Neuroradiol 2012;33:1007-13.

3. Zerr I, Hermann P. Diagnostic challenges in rapidly progressive dementia. Expert Rev Neurother 2018;18:761-72.

4. van Munster CE, van den Berg R, Weinstein HC. A dural fistula as a treatable cause of cognitive impairment. Neurohospitalist 2014;4:111-2.

5. Morparia N, Miller G, Rabinstein A, et al. Cognitive decline and hypersomnolence: thalamic manifestations of a tentorial dural arteriovenous fistula (dAVF). Neurocrit Care 2012;17:429-33.

6. Santillan A, Safdieh JE, Gobin YP, et al. Neurological picture. Bilateral thalamic venous hypertension caused by a tentorial dural arteriovenous fistula: endovascular treatment. J Neurol Neurosurg Psychiatry 2011;82:749-50.

7. Holekamp TF, Mollman ME, Murphy RK, et al. Dural arteriovenous fistula-induced thalamic dementia: report of 4 cases. J Neurosurg 2016;124:1752-65. 
8. Bhogal P, Duxbury O, Rangi P. Dural arteriovenous fistula (D-AVF): a rare cause of symmetrical bithalamic changes with free diffusivity changes. BMJ Case Rep 2014;2014:bcr2014011186.

Cite this article as: Zhang J, Duan H, Jin H, Leng Y, Chen J, Zhang W, Huang Y. Dural arteriovenous fistula, a rare cause of rapidly progressive dementia in a patient with bilateral thalamic lesions: a case report. Ann Palliat Med 2021;10(7):8371-8377. doi: 10.21037/apm-20-1481
9. Racine CA, Lawton MT, Hetts SW, et al.

Neuropyschological profile of reversible cognitive impairment in a patient with a dural arteriovenous fistula. Neurocase 2008;14:231-8. 